\title{
Investigating boron isotopes and FTIR as proxies for bushfire severity
}

\author{
SHAWN LU ${ }^{1}$, ANTHONY DOSSETO ${ }^{1}$, DAMIEN \\ LEMARCHAND $^{2}$, PAVEL DLAPA ${ }^{3}$ AND ROSS \\ BRADSTOCK $^{1}$
}

${ }^{1}$ University of Wollongong

${ }^{2}$ University of Strasbourg

${ }^{3}$ Comenius University

Presenting Author: ch1975@uowmail.edu.au

Bushfires play an important role in shaping Earth's natural systems. There is need for an accurate fire regime model to predict the impact of a climate-driven fire regime change. Current fire records are limited by the lack of proxies that can infer past fire severity reliably from sediment records, and are inadequate for showing how bushfire properties were affected by past climate variability. New fire proxies are therefore necessary. A key test to the viability of new fire proxies is whether they record fire characteristics in the affected soil before transportation to sediment records. We address this by testing Attenuated Total Reflectance- Fourier Transform Infrared (ATRFTIR) spectroscopy and boron (B) isotopes in soil clay fraction from Yengo National Park, southeastern Australia, as proxies for bushfire severity. The isotopic results were also compared to that of clay that reacted with experimental charcoal and ash. Yengo National Park had last experienced two bushfires in 2001/2002 and 1993/1994 fire seasons. ATR-FTIR spectroscopy shows that soil clay in the top $5 \mathrm{~cm}$ have similar kaolinite lattice and hydroxyl peaks despite experiencing different fire severity histories. Peak positions and intensities are not sensitive to bushfire severities, contrary to previous studies that show dehydroxylation peak characteristics at higher temperatures. This suggests that even in high severity fires, soil do not typically experience temperatures higher than the dehydroxylation threshold of $500{ }^{\circ} \mathrm{C}$. The aromatic: aliphatic organic peak ratios are higher for soil that experienced at least one high severity fire. This correlation does not extend beyond the top $5 \mathrm{~cm}$. At sites that experienced at least one high severity fire, clays show a $B$ isotope composition $\left(\delta^{11} \mathrm{~B}\right)$ up to $1.5 \%$ higher than those of other sites. This correlates most closely to clay that reacted with experimental charcoal leachate, showing that charcoal has greater impact than ash on the soil $\mathrm{B}$ isotope composition. This could possibly be explained by the increased ${ }^{10} \mathrm{~B}$ volatilisation from organic-rich charcoal leachate. These findings suggest that ATR-FTIR organic peak ratios and B isotope in soil clay preserve information of the most recent fire, and represent viable candidates as fire severity proxies. 